\title{
New business client acquisition using social networking sites
}

\author{
Przemyslaw Kazienko • Natalia Szozda • \\ Tomasz Filipowski • Wieslaw Blysz
}

Received: 28 April 2012 / Accepted: 4 February 2013 /Published online: 27 February 2013

(C) The Author(s) 2013. This article is published with open access at Springerlink.com

\begin{abstract}
The rapid development and expansion of the social services and social networking sites (SNSs) on the Internet has boosted interdisciplinary research on online communities as a part of social network analysis. Social networking creates a unique opportunity to establish new business contacts with people from unexplored markets to gain new customers or contractors. The goal of the paper is to present a new idea for acquisition of new customers in the business-to-business market using individual human relationships existing SNSs. In order to find an appropriate solution, the SCAN method (System for Client Acquisition via Social Network) has been proposed. This method is a B2B application to support new markets gaining process. It makes use of paths over human relationships that lead in the shortest and steadfast way from the searching company members to the potential clients represented by their selected employees.
\end{abstract}

\section{Responsible Editor: Ricardo Colomo-Palacios}

P. Kazienko $(\square)$

Institute of Informatics, Wroclaw University of Technology,

Wyb. Wyspianskiego 27,

50-370 Wroclaw, Poland

e-mail: kazienko@pwr.wroc.pl

N. Szozda

Wroclaw University of Economics and Research \& Engineering

Center Sp. z o.o., ul. Komandorska 118-120,

53-345 Wroclaw, Poland

e-mail: natalia.szozda@ue.wroc.pl

T. Filipowski

Wroclaw University of Technology and Research \& Engineering

Center Sp. z o.o., Wyb. Wyspianskiego 27,

50-370 Wroclaw, Poland

e-mail: filipowski.tomasz@gmail.com

\section{W. Blysz}

Research \& Engineering Center Sp. z o.o., ul. Strzegomska 46B, 53-611 Wroclaw, Poland

e-mail: wieslaw.blysz@rec-global.com
Keywords Client acquisition · Online social system · Social networking site $\cdot$ Business hubs $\cdot$ Marketing $\cdot$ Business market $\cdot$ Industrial market $\cdot$ B2B $\cdot$ Social networks

JEL M31 · M15

\section{Introduction}

The world of business changed drastically during the early 21 st century. Business success today requires increasingly the best possible Business Intelligence (BI) to compete in a global marketplace, where faster moving competitors are a constant threat. Fortunately, we have the Internet for a competitive advantage (Vine 2000). It is important for companies to transform Internet resources into business success. Companies are pushing information out to consumers to a social process of information sharing (Meredith and O'Donnell 2010), but they also gather information about competitors, employees, clients and potential markets. Currently, one of the fastest growing areas in the Internet Business Intelligence is social media (also called social networking). Companies use it to communicate with the market but also to gather information from there. Social networking sites (SNSs) are considered as "the future of marketing" by the giant such as Procter \& Gamble (Sabherwal and Becerra-Fernandez 2011).

The use of SNSs such as LinkedIn or Xiang for business purposes, i.e. to gain new customers is particularly noteworthy. Many researchers (Gillin and Schwartzman 2011; Miller 2012; Schaffer 2011) see this potential but they omit essential questions: how to acquire new customers in practice, how to accomplish it? In this study, we do not simply use well-known communication channels and typical SNS functionalities like groups in LinkedIn since they all require the goals, tools and business relationships being already pre-defined. We want to go a step forward and facilitate establishment of new, unknown links, through seeking new markets. This is especially important for professionals cooperating in the B2B market, 
particularly while entering into an unexplored market and/or searching for new ones. This is additionally complicated if business needs change relatively frequently and the company conducts diverse business activities. In such case, a new type of IT system is required: it should locally manage the evolving business requirements and simultaneously automatically integrate it with and make use of external SNSs.

With reference to the above, the goal of the article is to present a new IT system supporting sales managers, who, through social networking sites (SNSs), want to find relationships with potential clients represented by their selected employees. The proposed solution is particularly suitable for companies looking for new relations with potential clients or contractors in the business market, where continuous finding potential partners is crucial for sustainable development.

\section{Problem description}

Companies that operate in the business markets (called also the industrial markets or the $\mathrm{B} 2 \mathrm{~B}$ - business-to-business markets) acquire goods and services to be used in the production of other products or services which are sold, rented or supplied to other companies (Kotler and Keller 2006). The sales process often takes longer (Hedaa 1996) - up to 2 years and is based on building relationship between the limited numbers of involved employees. Important aspects are relationships, good collaborations within business networks (Heinrich et al. 2011) which are built among individuals representing the cooperating companies, not between firms as wholes. As a result, there is a risk of losing customers when a single employee is laid off. To acquire a new customer especially in a new, unexplored industrial market, it is necessary to overcome the entry barrier (Karakaya 2002), which in most cases strongly depends on the social factor - trust (Gómez and Martínez 2010). A key element for suppliers is to establish a new relationship with potential customers. To build such relationships between the company and its customer in the business market, the selection of the targeted customers is essential; it is the first stage of a customer life cycle relationship - the identification stage. The company will devote research efforts to understand as much intelligence as required about the customer and its industry (Katsioloudes et al. 2007). One of the key things that affect the new contract is to find the right person interested in or responsible for buying products or services. The features to be considered for that purpose are in particular: (i) the department, which the person represents, (ii) the authority in the organization and (iii) the type of personality. In practice, one can see the correlation between personality type and job title.

Thus, the emphasis in the initial phase of the sales process should be put on the identification, searching for people who are worth cooperating with. Exploration a contact requires determining specific search criteria. The key points which have an impact on the establishment of closer human relations are: nationality, foreign languages spoken, domain knowledge \& experience, expertise, abilities, interests, position, education level, standing among the society or community, etc. Searching for influential people as the potential customers can be supported by various knowledge bases (e.g., 'Who is who') and recently also by online social networking. It includes most of the information, which you are looking for to find the right people to get in touch with a potential client. Additionally, in many cases the searching process should be repeated periodically sometimes quite frequently, what requires specialized company's internal IT services to be integrated with external SNSs.

\section{Related work}

Social networks existing especially in social networking sites (SMSs) have emerged as a major social phenomenon within the society and their position is becoming stronger and stronger with the growth of the number of their users (Musiał and Kazienko 2013). Boyd and Ellison (2007) define SMSs as web-based services that allow individuals (i) to construct a public or semi-public profile within a bounded system, (ii) to articulate a list of other users with whom they share a connection, and (iii) to view and traverse their list of connections and those made by others within the system. They pay special attention to network connections (called also links, relationships or bounds). It gave birth to a new model of communication and acquisition of knowledge, which represents an opportunity for knowledge management initiatives (Sie et al. 2011). Besides personal purposes, SNSs are also being increasingly internally developed by companies. There are four main areas of online social networks used in businesses: marketing (Leskovec et al. 2007), labour market (Montgomery 1991), connecting with customers (Goldbeck and Hendler 2006), communicating with people within a business environment (Robins and Alexander 2004).

The most common use of SNSs in business is marketing; it includes especially: informing, sharing information and opinion, and promoting. SNSs are quite widely used to attract new employees and capture the targeted market of those who are the most valuable. Thus, they provide some unique opportunities, which many companies recently started to exploitexpansion of the existing business and searching for new markets. SNSs can be a good resource for finding suitable influential people at potential business customers. Baird and Parasnis (2011) suggest that social networks should be a communication channel for companies to connect and collaborate with customers, and leverage their influence as brand evangelists. Domingos and Richardson (2002) pay attention to determine what potential customers to collaborate with on the market in order to optimize marketing and sales decisions. 
The modern companies recognize the opportunity to develop their businesses through social networks more and more. According to research conducted by IBM Institute for Business (2011) more than $79 \%$ of companies have their profiles on SMSs. Hence, it is possible to use this data from the bottom up by listing the people who work in desired companies.

Many researchers see the potential of using SNSs. Miller (2012) emphasizes the importance of using SNSs such as LinkedIn for business purposes which makes them an essential part of B2B digital marketing plan. Schaffer (2011) stands out new client acquisition as one of the popular LinkedIn objectives. According to him, every employee can be a sales person. Gillin and Schwartzman (2011) argue that most of social media profiles are public, so it can be a useful way to get past the traditional gatekeeper departments like sales, support, and public relations, who often try to restrict access to decision makers. It can be used to find people with connections to company's internal social network or simply as a starting point for more detailed analyses. One of more useful features of profiles are the links to social communities (groups) the site member belongs to. One can use this information to scope out the issues being of interest for the whole groups or to establish new direct links to individuals. It especially refers services focusing on professional activities of their users are LinkedIn or GoldenLine.

To search profile in the network (on the Internet) of potential, new customers, it is necessary to use query-based applications in order to obtain useful data (Gómez-Berbís et al. 2011). It is crucial to find persons (potential clients) for whom the company is providing services to meet their needs (GarcíaCrespo et al. 2010a). This possibility requires a system that should be integrated with the CRM internal services. The social networks can be used to establish new customer relationships, whereas a platform between the supplier and the customer creates the possibility of interaction (García-Crespo et al. 2010b). The creation of a business relationship cannot be completed without the confidence that can be measured (scoring, ranking, rewarding, punishing or gathering behavioral information using) through multi-factor trust and/or reputation models (Gómez and Martínez 2010). Building systems to interact and find potential clients in the network is an interdisciplinary issue that combines the tasks from the various fields such as IT, social-media, sociology, management, marketing and other management disciplines (Takac et al. 2011).

In social networks, people influence one another and this principle can be used to analyse their positions. The value of the potential customer (member of the organization) is assessed by the position in the network structure. (Kazienko et al. 2009). It can be observed that many SNSs provide the most integrated and simultaneously diverse communication channel between partners. However, the main problem is how to find the right person, a candidate for the future partner, i.e., somebody with whom the contact allows to establish new business cooperation. The present studies have shown the possibility of using functionality of SNSs. The companies' needs are adapted to the opportunities offered by social networks. To improve the efficiency of searching new markets, contacts or clients for business purposes, it is necessary to manage varying needs of the company. Most research in this matter, e.g., Gillin and Schwartzman (2011), Miller (2012), Schaffer (2011), focuses on the contact search across known direct links or social groups. Lack of the knowledge of the market or group prevents from using SNSs for new client acquisition. For that reason, the integration of external data from SNSs with internal CRM system is essentially expected.

In order to find an appropriate solution for above problems the SCAN method (System for Client Acquisition via Social Network) is proposed.

\section{The SCAN method}

In the modern global market, the process of finding and gaining new business partners and spreading company activities on unknown and promising areas became more and more crucial. To address the distant client acquisition problem we present a new SCAN system (System for Client Acquisition via Social Network). SCAN is a B2B application for boosting and supporting new markets gaining process. Based on (i) the data extracted from SMSs, (ii) information about own employees' connections and (iii) the social graph analysis methods, the SCAN method finds paths that lead in the shortest and steadfast way from our company members (users of SNSs) to the potential clients represented by their selected employees. As a result, it maximizes probability of initializing new successful business cooperation.

For that purpose, a given company should specify their needs (see "Search Profiles") and utilize the SCAN system, which architecture and concept are described in "SCAN Architecture".

\section{Search profiles}

At the beginning, a certain business need has to be identified: a company is looking for new business partners to fulfil some particular business strategy. It may be a subcontractor producing some hi-tech components, a rare and high quality service provider or a potential customer of our products or services, especially from a new business market unexplored by the company. The company may also look for a supplier in its close area or a distant but cheap manufacturer. If the company considers gaining new international or very competitive markets to offer its products or services, it has to find some entering ways. No matter what is the purpose (finding a new supplier or customer), the initial step is to 
create a client/supplier search profile: "who are we looking for?" (Fig. 1). This is the most important user interface to communicate with the SCAN system.

We propose three main components of such a client search profile. In the first part of the profile (business profile), a user describes the business features of the desired partners. This part is, in fact, the core of a request and specifies what kind of company the user would like to make business with. Hence, you need to point, which economy sector you want to operate in, as well as what regions of the world are your recent expansion destination - it is typically a country, e.g., Germany. You may also provide some requirements about a presence in the stock market or finance conditions, if they are public. At the end, you can point a market branch, e.g., automotive industry and even a particular company, e.g., Volkswagen, you are interested in cooperation with.

When the system knows what you are looking for, it is time to focus on how the destination companies can be reached. The second and third part of the search profile describes so called link person. You can describe a person that according to their knowledge will maximize the probability of establishing a new successful cooperation. There may be very solid reasons to believe that only a high educated person will fully understand your company hi-tech solutions and be able to convince potential partners to cooperate with. For a very trivial reason, you may wish to communicate only with people who speak certain languages. It may be also a good idea to contact with some skilled engineer first, instead of going directly to the head management. This part of the profile is called the personal profile and consists of skills, expertise, education and company position of individuals.

The third part of the profile refers to the social position of the link person. It is also the most complex part and requires the sophisticated research attention. It is closely related to social network analysis (SNA) and estimation how important a node in the network is and how to reach this node starting from a given point. However, it is not trivial and intuitive, which social measure to apply in order to find the suitable and efficient way in to the company or the whole market sector. Moreover, the answer for this question strongly depends on what exactly you are looking for, i.e., either for a single contractor - provider, or a small or big company-potential customer or even as many individual customers as possible, etc.

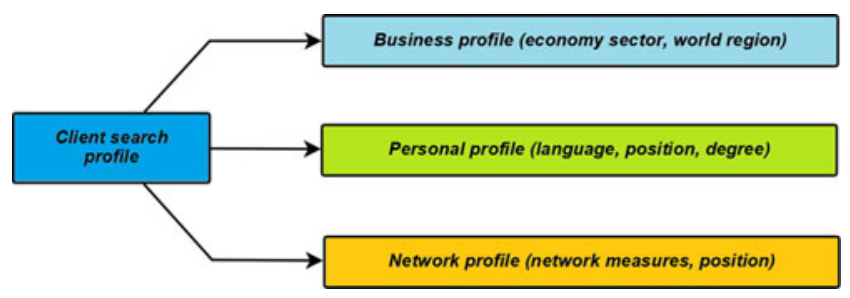

Fig. 1 Client search profile
There is a vast range of structural measures describing importance of a node, i.e., social entity (a human or a group of people), in the social network. In the literature the following are described among others (Carrington et al. 2005; Scott 2000): node in and out degree, betweeness, closeness, page rank, node position, clustering coefficient- they are only some of the most popular ones. However, it is not obvious which one of them is the most suitable in a given solution (Musiał et al. 2009).

Overall, three general positions of the person in the network can be proposed: inside the client organization (Fig. 2a), outside of both a user company and clients (Fig. 2b) and a hybrid approach mixing both methods (Fig. 2c).

Case $a$ (Fig. 2a) describes the case when for some business reasons we are looking for a contact person in a particular company. It is the most desirable case since then you have a direct contact inside your customer organization. Simultaneously, it is a quite restrictive situation from the application point of view, especially when you may face a lack of data problem. One must take under consideration that the computer system may have only a sparse or limited data about some particular and foreign markets. That is why the rest of the search profile (business and personal parts) should not be too specific in this context.

If you need to be restrictive in terms of non-social search dimensions, using the case $b$ (Fig. 2 b) will probably provide better results. For instance, it may be reasonable to find a person who is a female automotive manager with an engineer diploma. On some markets it may be quite a problematic task. Then you may weaken or even clear the social criteria to search for a person related somehow with interesting companies, such person does not have to necessarily be a member of any. Obviously, the person like this may suffer from weak connections at the management level in these companies. From the other point of view, knowing a person with broad but weak contacts on the whole desired market may be more useful than having one with strong connections but only inside one organization - it depends on situation and is up to the system user decision.

The hybrid profile combines two previous approaches (Fig. 2b). You are looking for a person strongly embedded in a given company but at the same time with wide relationships on the whole market. Before we decide to use this case, it is necessary to note that such people are rare and precious. Usually, the personal and business criteria should be loosened as much as possible when combined with the hybrid approach.

\section{SCAN architecture}

Accomplishing the client search profile creation process effects with an electronic criteria representation. This digital document became an input for the SCAN system-step 1 in Fig. 3. 
Fig. 2 "Link" person positions

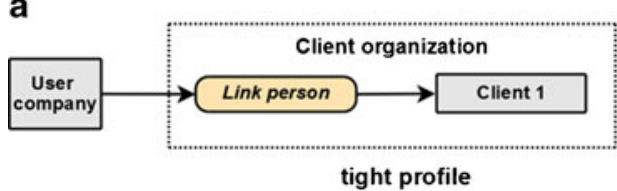

b

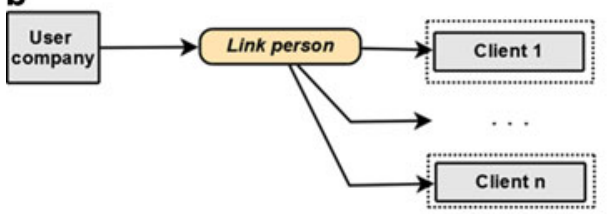

c

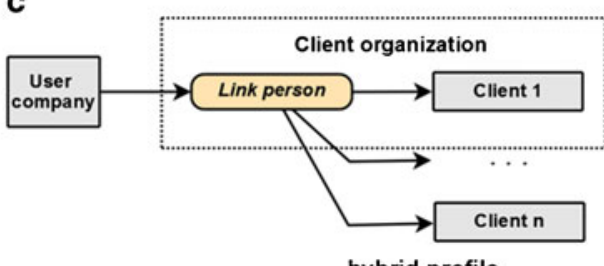

loose profile

Before the matching engine starts its work, the system needs more data, yet. As we mentioned in the beginning of this article, SCAN searches for results based on social web services using user search parameters stored in search profiles. Thus, the very important and crucial system part is a web crawler (step 2 in Fig. 3). Its task is to browse selected parts of the Internet and search for suitable data. Efficiency, web structures dynamic, access permissions and legal aspects have to be handled carefully, see "Feasibility Study". At the end of its work, a web crawler provides the structured data about the market members and their social connections. This data is stored in the Raw data database.

We have already discussed some possible locations of the end points (see Fig. 2) of our paths. However, the system still needs more information to perform efficient search - in particular so called starting points are necessary. Having in mind that the system's main task is to provide a social path from our company to the potential client, for the starting point we make an assumption that each of them has to lie in user internal company social network. In other words, by starting points we will mean selected user company employees. In the modern companies, one may find a wide range of electronic data sources about employees. A traditional CRM system seems to be the most sufficient for a system like SCAN (see the transition 3 in Fig. 3). In fact, most often CRM system does not provide complete information about internal organization structure. Nevertheless, the data stored in the CRM database is by default strongly related with company sales, marketing and communication processes with client and business partners. (Heinrich et al. 2011). For that reason, it contains precise information about your employees engaged in contacts with external world and these people can be used to establish new relationships with new business customers or contractors. Moreover, a good CRM system provides not only data about our sales, management and PR employees, but it also bonds them with our actual customers and partners. This is important information that may be utilized by the SCAN system. Simultaneously, you have to remember that not all employees (system users) are willing to share their business contacts. Especially, when your company offers benefit programmes to workers, e.g., special bounties and perks for each sale or business contract, see "Feasibility Study".

At this point, we assume that the SCAN system has an access to both - client Raw data and Traditional CRM databases. These both varied and complicated data sources are merged in the Social network integrator (SNI) module (block 4 in Fig. 3), which provides unified and consistent data for further analysis and processing. Since Raw data came from different external systems in various data formats, the goal of

Fig. 3 An overview of the SCAN architecture

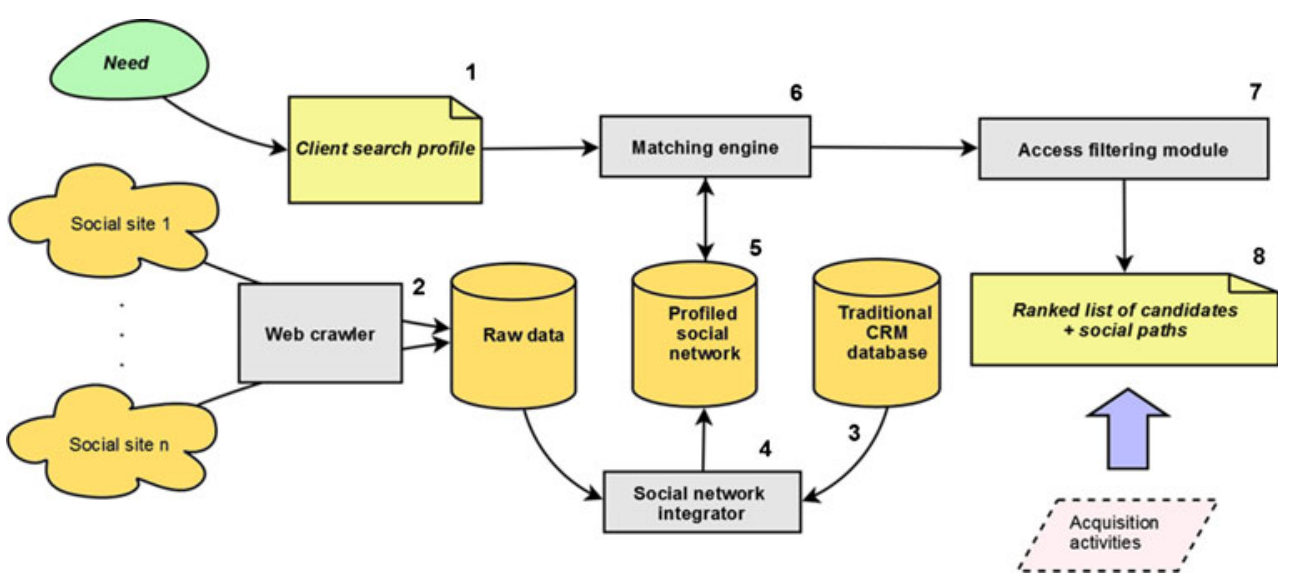


the integrator is really tough. It becomes even more complicated if one realizes that the number of data sources may rise, formats can change and not all data may be stored locally in the Raw data repository. It may happen, for instance, that some parts of Raw data can be virtual-accessible only online. The CRM-related part also depends on changing data environments. Companies may use a lot of different CRM systems, so the SCAN system has to be adapted to particular company CRM requirements.

The social network integrator module (SNI) is presented in Fig. 4. The basic idea is to introduce extendable sets of raw data parsers (RDP) and CRM parsers (CRMP). Their task is to provide data in the unified form for the main data integrator (MDI). The main data integrator, in turn, filters and cleans the data. It finds links between data entities, creates necessary aggregations and gathers information about particular objects (people, companies, etc.). MDI is also responsible for comparing old and new data and updating the profiled social network (PSN) in the intelligent way. If a given person (our employee or a person representing a potential new customer) already possesses its representation in PSN and new data about him or her is found in some social systems, SCAN has to recognize it and update the existing representation accordingly instead of creating a new one. The same problem comes out for other entities like person's connections, actions and artefacts. Avoiding data redundancy is an important issue and has to be handled in order to preserve proper results.

The output of the social network integrator is a profiled social network (database 5 in Fig. 3). A common social network consists of a finite set of nodes (external people, employees, system users) and a set of edges (connections, social bonds) between them. Information about nodes (employees of the user's company, potential business partners and people related to them) can be easily extracted from SMSs or corporation information systems like CRMs. Edges between the extracted nodes can be created and weighted based on various premises. The fact of being in the same team, sharing the same resource or space, having a common activity or mutual communication (email, SMS, telephone call, forum discussion, etc.) may affect in an edge between participating nodes. However, a simple graph representation does not contain enough information for the SCAN purpose. Since the client search profile consists of business, personal and network (social) sub-profiles, the graph has to be profiled, i.e., enriched by information about the node (person) and its career.

The core of the SCAN system is inside the matching engine (block 6 in Fig. 3). Its basic task is to find people who match our needs the most, based on a given search profile. We may conceive it as a parameterized algorithm or model, where a client search profile is the parameter set and a profiled social network plays the role of data input. The SCAN system matches a given search profile and using its content and internal rules searches within the stored data. There are three basic steps that have to be performed during each search. SCAN does not assume that users possess any knowledge about the new business market they are interested in. Thus, the system should find suitable companies that best match user preferences. Having the data set of filtered companies, the probability (score) of successful accessing each of them has to be computed in order to create a ranking of them. For that reason, so called destination link persons have to be found. This is the phase where information about link person position is used, see Fig. 2. Finally, in the third step, the SCAN system has to calculate optimal paths from the user company to the selected link persons. The basic assumption is that a path can start on any of the user company employees registered in the database. By a registered employee we mean a person who works or worked for the user's company and who voluntary shares and stores their social business contacts in the system. The legal and motivation aspects of such act of sharing are discussed in "Feasibility Study". On this stage of data processing, the main system task - finding the best connection from the user
Fig. 4 Social network integrator module

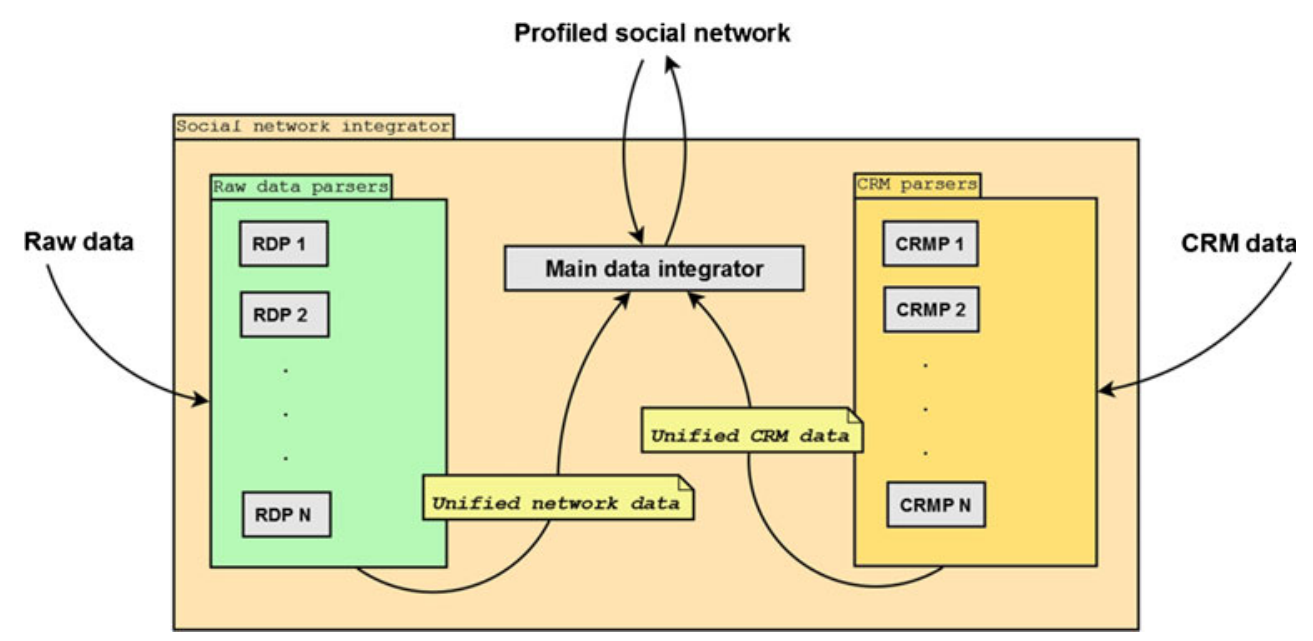


company to the potential business partner - can be perceived as finding the best link person and the best social path from the user to this destination person. By the best link person, we understand the one that maximizes the probability of establishing successful cooperation between companies, for instance, a person with the best social connections with the company board, highest authority or strongest position in the company network, etc. Similarly, the best social path is the path that also maximizes the probability of establishing contact between one of the user company employees and the link person. Obviously, both of these factors (a link person and a social path) influence the final probability of establishing fruitful cooperation. Focusing only on one of them may not result in maximizing the final success probability. In other words, even the most popular and influential person in the area of potential business partner is useless if one cannot efficiently contact with him or her. Also, the shortest and most convenient path from the user company to the person in the potential partner closest social area does not matter, if this person cannot contact us with the partner executives.

An output of the matching engine (a ranked list of candidates and social paths) is passed from block 6 in Fig. 3 to the access filtering module (block 7). This module is responsible for the information privacy management. It is likely to happen that some of the returned social paths will start on company employee other than the current user. Depending on the company's internal policy and the decision of the particular employee, a path (a list of private contacts) can be shown directly only to the current system user or the request for mediation can be passed to the contact owner.

\section{Use case}

A case study on new business partner searching is presented to facilitate understanding the SCAN process. This process starts from the initial business need specification and ends at the moment of the first real contact between the users company and a new business partner, see Fig. 5.

Jan is an employee of the Umbrella company. He occupies a position of sales manager. Umbrella is a mediumsized textile producer from Central Europe cooperating with few local cloths manufacturers. Since the company is currently facing an overproduction problem, it looks for new markets for their products.

Cloths produced by the company business partners are successfully traded on the Scandinavian markets. Costumers praise especially the fabric quality. Thus, the Umbrella's management is willing to launch cooperation with some Scandinavian cloths manufacturers and the sales department receives the task to find new business partners.

Jan is an innovative person aware of the existence of the SCAN system just introduced in his company. He decides to make use of it. If Umbrella has already some business contacts with local cloths producers, he thought, and the local cloth producers have their own contacts on the Scandinavian market, there has to be a path leading from Umbrella to potential partners in Scandinavia. Keeping all above in his mind, Jan launches the SCAN front-end client and types his query, see Fig. 1. He provides that he is looking for a cloths producer located in Scandinavia. He also assumes that he has only a partial knowledge about this local market so he does not specify any company names. This is enough to describe requested client business profile.

Jan believes that the best chance for success would give him an open minded ambitious person occupying a middlelevel position in the management structure. Such a person is probably relatively young and well educated, he thought. Possibly an economics graduated person aged between 25 and 35. Jan speaks fluently English, German and Spanish but he does not communicate in any Scandinavian language. Hence, the next query parameters will be the suitable language spoken. Finally, the client personal profile has been specified enough.

Jan is afraid that not all potential business partners may be familiar with central European companies and the quality of their products. He needs a person $X$ located inside a particular organization (see Fig. 2) relatively close to the top management and trusted in a whole company. $X$ should possess the significant social position denoted by the high values of $X$ 's structural centrality measures. On the other hand, Jan needs someone who is at least familiar with central regions of Europe. Any business or private contacts in this part of the world will be welcome. In this way, Jan defined the client network profile and he accomplished the client search profile creation process.

Now, it is the system time to take the control over. Jan's query is being parsed and processed by the SCAN system. It searches for suitable companies in the Scandinavian market. Then, it finds all possible paths from the Umbrella company through the profiled social network to the destination companies just found. SCAN rates paths regarding their length and connection strengths, in order to estimate probability of passing the message from the beginning of the path to its end. It also ranks persons at the destination in terms of matching the social and personal profile provided by Jan in his query.

Finally, the ranked list of names and contact information is provided to Jan. At the top of the list, Jan founds Marit. She is a 27 years old promising young junior manager in the Klær Company, holding a master's degree in economics. Marit speaks fluently German and has just returned from her maternity leave. Jan thinks that she may be eager of new challenges and willing to take opportunities. Moreover, she works inside the company and is a very popular and respected person - she has high centrality measures. That matches Jan's expectations. 
Fig. 5 Use case diagram

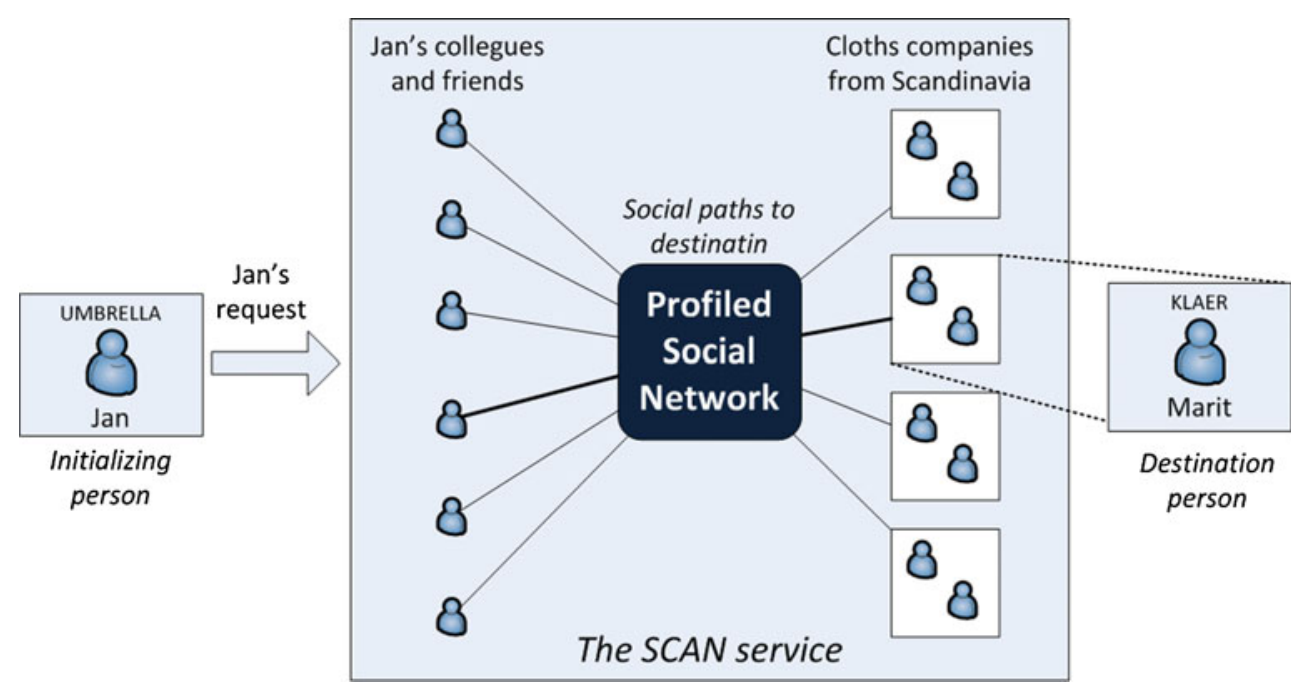

Finally, Marit has no direct business contacts in Central Europe but a lot of her private acquaintances are from Poland and Czech Republic. Jan believes it should be enough to establish an initial contact.

Jan has a possibility of the direct contact by means of the email address returned by SCAN. However, the social distance between him and Marit equals four people - there is no common colleague of them both, who he could quote in his email message. Hence, he decides to reach Marit step by step through the social path. The SCAN system reports that the overall approximate probability of passing Jan's message through the path to Marit is 0.76 . It seems to be a reasonable value for Jan and Jan sends an email to his first contact from the path with the appropriate request to pass it over up to Merit.

\section{Feasibility study}

Any implementation of the SCAN system should respect some objective and subjective restrictions and circumstances. Overall, socio-psychological, organizational ("Socio-psychological and Organizational Factors") and technical factors ("Technical Issues") need to be taken into consideration and some difficulties should be overcome for successful deployment of the SCAN system.

\section{Socio-psychological and organizational factors}

There are many strengths and weaknesses of the proposed solution. Feasibility study of that venture is associated with socio-psychological and organizational barriers. The first of these arises from the human nature, behaviour and attitudes of individuals responsible for contacts with the customers, while the second is related to limitations of the business or social networking.

Among the socio-psychological factors: cultural, foreign language factors, barriers in contact with the customer, ability to share information and problems in using social networking need to be addressed. These regarding the organizational or the national culture may even break the relationships with the customer. The next obstacle is lack of foreign language knowledge, which creates inability to communicate with potential clients. The major limitation are resistance and difficulties in connection with the customer's relationship resulting from the psychological nature of the salesman like shyness, difficulty in establishing new contacts, starting conversations, etc. A salesman should be characterized by openness and willingness to share information about the established contacts and upload them to the company's CRM system, ability to use new technologies to find new contacts by searching SNSs, etc. For this purpose a trusty IT system must be created with the limited access for other company members.

In the case of a new system, firstly the financial viability can be judged. New solutions have to be in line with the general company's strategy, way of businesses management and organizational form of enterprise (structure). On the side of the organization, it is to impose an obligation to collect information and complement the CRM system about established and held customer relations with different external companies. They are the input data which allows starting the search for a new relationship by examining strength of association between objects. The proposed solutions (the SCAN method) have to be an integrated part of the CRM system; it must be possible to integrate all cooperating IT systems.

There is another factor on the organizational side on which the company implementing the proposed system will have no influence, namely, incomplete data in the social network, e.g., LinkedIn. There will always be a risk that the data preserved in SMSs are not reliable, incomplete or even inaccurate. 


\section{Technical issues}

A brief feasibility study on data availability for five big external social networks is presented in Table 1.

The main technical challenge is the integration of data from SNSs and company's CRMs as well as identification of the same people among many social services. The perfect case will be to have internal network accounts of the company employees matched with the CRM database by employees themselves. This is, however, unlikely and a matching algorithm has to be used, see Fig. 4. In other words, having e.g., names, surnames, telephone numbers or email addresses, the system compares them over different SNSs and finds accounts that belong to the same person with high probability. Obviously, we would need to accept some small error level caused by SCAN. Extending the account match with human support would significantly reduce the error rate and increase system accuracy.

\section{Quantitative efficiency factors}

Social and business processes and relations are complex by their nature. That is why in the real world a lot of different factors can affect system accuracy, precision or efficiency. Some of the them-technical ones can be quantified, e.g., using some common metrics like precision and recall. The former denotes to what extent the system output (destination persons in the desired companies and paths to them) is really relevant and does not contain any wrong data. The latter is a measure of completeness - shows whether all relevant contacts were identified.

From the technical point of view, gathering representative sample of data about overall communication and contacts between employees of different organizations is not a trivial task. All systems suffer from the incompleteness and inconsistencies of data since they are developed for some specific purposes. Those purposes affect users' behaviours and obviously cause data biases. One should not mismatch a slice of reality represented by particular data source with reality as a whole. In general, the completeness, credibility and diversity of datasets are very important for the SCAN efficiency. All those factors should be measured and boosted by the system integrators. The more different SNSs we successfully integrate with SCAN and the more complete and comprehensive is our own CRM datasets, the better the SCAN accuracy and precision. Additionally, the more employees share their business contacts inside our company, the bigger the SCAN recall.

The data processing quality is as important as data quality. The SCAN novelty feature utilizes relational dimension of the gathered information (social networks). Social and network measures are then the core of the relational data processing. To evaluate node importance and usability suitable formulas need to be applied. There are many local and global structural measures as the social indicators for social networks (Carrington et al. 2005; Musiał et al. 2009; Scott 2000; Wasserman and Faust 1994). Local measures like node degree are easy and fast to be calculated whereas the global ones (PageRank, Social Position, Betweeness Centrality) seem to be more informative in terms of brother context of the whole network and node usefulness for information transfer from organization to organization, see (Musiał et al. 2009) for measure comparison. The selection of the best social measures for the purpose of the SCAN service is not trivial and requires deeper theoretical stdies as well as some extensive experimental research on a real system implementation.

Table 1 Large social networking sites (SNSs) on the Internet

\begin{tabular}{|c|c|c|c|}
\hline Service & Crawler/API & Limitations & Advantage \\
\hline 123People.com & $\begin{array}{l}\text { Crawler possible, no } \\
\text { API }\end{array}$ & Search features: Given name is necessary, country & $\begin{array}{l}\text { Search output: Public email address, related } \\
\text { persons (not common), links, blogs, photos } \\
\text { and videos, public documents, tag cloud }\end{array}$ \\
\hline Facebook & $\begin{array}{l}\text { Possible but strictly } \\
\text { restricted, Facebook } \\
\text { app ID required }\end{array}$ & $\begin{array}{l}\text { Access Token is necessary for your application, } \\
\text { only your neighbours are accessible and users } \\
\text { connected to your application }\end{array}$ & Recently the largest SNS on the Internet \\
\hline LinkedIn & $\begin{array}{l}\text { Possible but restricted, } \\
\text { LinkedInAIP, } \\
\text { additional agreement } \\
\text { negotiable }\end{array}$ & $\begin{array}{l}\text { Access Token is required, up to the } 2 \text { nd level deep } \\
\text { from the logged-in user }\end{array}$ & $\begin{array}{l}\text { The largest worldwide SNS with professiona } \\
\text { profiles }\end{array}$ \\
\hline Xing & $\begin{array}{l}\text { No public API but some } \\
\text { are provided by } \\
\text { partners }\end{array}$ & $\begin{array}{l}\text { Only for logged-in users, } 2 \text { nd level deep, query: } \\
\text { country, city, industry, and for the premium } \\
\text { account additionally: company, language and } \\
\text { employment status }\end{array}$ & $\begin{array}{l}\text { Auto search available, high level of possible } \\
\text { integration }\end{array}$ \\
\hline Yellow pages & $\begin{array}{l}\text { No API, crawler } \\
\text { possible }\end{array}$ & $\begin{array}{l}\text { Search by location and business type, company } \\
\text { name. Only company data }\end{array}$ & Access to company contact data \\
\hline
\end{tabular}


A separate problem is the system effectiveness and efficiency. The main goal of the SCAN system is the support at establishing successful cooperation between companies, which can be simply measured by the number or value of new contracts - it is an effectiveness measure. Efficiency, in turn, can be evaluated by means of necessary time, resources and costs consumed to reach the final SCAN goals- new contracts. It strongly depends on other quantitative measures like size and quality of data sources, speed of hardware and software platforms, efficiency of workers engaged, ability of the organisation to make use of new contacts, see also "Socio-psychological and Organizational Factors" and "Technical Issues". All of them influence the final success and enable to establish the right key performance indicators (KPI).

\section{Conclusions}

More and more companies use social networking to win new businesses. Even $44 \%$ of companies worldwide say that they successfully use social networks to acquire new clients (Marketing UK 2011). Those companies are roughly $11 \%$ more likely to report increased revenues and profits than those that do not use social channels to find new business (Marketing UK 2011). This creates new unique opportunities for enterprises to access new business markets by means of social links stored in social networking sites (SNSs).

The main goal of the new SCAN system (System for Client Acquisition via Social Network) is to support the sales managers to find social paths leading in the shortest or most efficient way to the potential clients via social media. Using that method a salesman should understand who the most desirable customers are, connect with them in the right ways and take the best action to maximize success at selling to or buying from them some goods or services.

The novel SCAN method, in opposite to some existing business matching services provided by LinkedIn or Xing, exploits internal company's data, which is not available for external SNSs. It facilitates potentially more efficient acquisition of new business customers. The SCAN system introduces and utilizes a whole new dimension of private and business relations between people. It uses sophisticated social network analysis techniques to find the optimal way from the user company (concrete individuals) to its potential new client. Moreover, SCAN not only finds the company we need, like LinkedIn or Xing do, but it maximizes probability of new cooperation establishment by finding the proper social path - the gateway - that leads from our company employees to the right people at the right positions. It means that SCAN goes a step forward and extends the features recently provided by existing SNSs.
The proposed solution is the essential step in integration of internal CRM systems and IT services of the sales department with external SNSs to search for relations with potential clients or contractors. However, there are some constraints such as technical or socio-psychological and organizational factors that can negatively affect the usefulness of the SCAN method; see "Feasibility Study".

Acknowledgements The work was partially supported by The Polish National Center of Science, the research project, 2010-13. The publication has been prepared as part of the project of the City of Wrocław, entitled D "Green Transfer" - academia-to-business knowledge transfer project co-financed by the European Union under the European Social Fund, under the Operational Programme Human Capital (OP HC): sub-measure 8.2.1.

Open Access This article is distributed under the terms of the Creative Commons Attribution License which permits any use, distribution, and reproduction in any medium, provided the original author(s) and the source are credited.

\section{References}

Baird, C. H., \& Parasnis, G. (2011). From social media to social customer relationship management. Strategy \& Leadership, 39 (5), 30-37.

Boyd, D. M., \& Ellison, N. B. (2007). Social Network Sites: Definition, History, and Scholarship. Journal of Computer-Mediated Communication, 13, 210-230. doi:10.1111/j.1083-6101.2007.00393.x.

Carrington, P., Scott, J., Wasserman, S. (2005). Models and methods in Social Network Analysis. New York: Cambridge University Press.

García-Crespo, A., Colomo-Palacios, R., Gómez-Berbís, J. M., \& GarcíaSánchez, F. (2010a). SOLAR: Social Link Advanced Recommendation System. Future Generation Computer Systems, 26(3), 374-380.

García-Crespo, A., Colomo-Palacios, R., Gómez-Berbís, J. M., \& Ruiz-Mezcua, B. (2010b). SEMO: a framework for customer social networks analysis based on semantics. Journal of Information Technology, 25(2), 178-188.

Gillin, P., \& Schwartzman, E. (2011). Social Marketing to the Business Customer: Listen to Your B2B Market, Generate Major Account Leads, and Build Client Relationships. New Jersey: Wiley.

Goldbeck, J., Hendler, J. (2006). Film Trust: movie recommendations using trust in web-based social network., Proceedings of Consumer Communications and Networking Conference, IEEE, 282-286.

Gómez, M. F., \& Martínez, P. G. (2010). Towards pre-standardization of trust and reputation models for distributed and heterogeneous systems. Computer Standards \& Interfaces, 32(4), 185-196. doi:10.1016/j.csi.2010.01.003.

Gómez-Berbís, J. M., Colomo-Palacios, R., José Luis LópezCuadrado, J. L., González-Carrasco, I., \& García-Crespo, Á. (2011). SEAN: Multi-ontology semantic annotation for highly accurate closed domains. International Journal of the Physical Sciences, 6(6), 1440-1451.

Hedaa, L. (1996). Customer acquisition in sticky business markets. International Business Review, 5(5), 509-530.

Heinrich, B., Zellner, G., \& Leist, S. (2011). Service integrators in business networks? the importance of relationship values. Electronic Markets, 21(4), 215-235.

IBM Insitiute for Business Value Analysis (2011) CRM Study. 
Karakaya, F. (2002). Barriers to entry in industrial markets. The Journal of Business and Industrial Marketing, 17(5), 379388.

Katsioloudes, M., Grant, J., \& McKechnie, D. S. (2007). Social marketing: strengthening company-customer bonds. Journal of Business Strategy, 28(3), 56-64.

Kazienko, P., Ruta, D., \& Bródka, P. (2009). The Impact of Customer Churn on Social Value Dynamics. International Journal of Virtual Communities and Social Networking, 1(3), 60-72.

Kotler, P., \& Keller, K. L. (2006). Marketing Management (12th ed.). New Delhi: Pearson Education.

Leskovec, J., Adamic, L.A., Huberman, B.A. (2007). The dynamics of viral marketing. ACM Transactions on the Web, 1(1). Article 5. doi: $10.1145 / 1232722.1232727$.

Marketing UK. (2011). http://www.marketingprofs.com/charts/2011/ 5355/more-brands-using-social-networking-to-win-new-business.

Meredith, R., O’Donnell, P. (2010). A Functional Model of Social Media and its Application to Business Intelligence.15th IFIP WG8.3 International Conference on Decision Support Systems, IOS Press.

Miller, M. (2012). B2B Digital Marketing: Using the Web to Market Directly to Businesses. Indianapolis: Pearson Education, Inc.

Montgomery, J. (1991). Social networks and labor-market outcomes: toward and economic analysis. American Economic Review, 81 (5), 1497-1418.

Musiał, K., Kazienko, K. (2013). Social networks on the Internet. World Wide Web, Vol. 16, Springer, doi :10.1007/s11280-011-0155-z.
Musiał, K., Kazienko, P., Bródka, P. (2009). User Position Measures in Social Networks. The third SNA-KDD Workshop on Social Network Mining and Analysis, KDD 2009, ACM Press, Article no. 6, 2009.

Richardson M., Domingos P. (2002). Mining knowledge-sharing sites for viral marketing. KDD'02, ACM, 61-70.

Robins, G.L., Alexander, M. (2004). Small Worlds Among Interlocking Directors: Network Structure and Distance in Bipartite Graphs. Computational \& Mathematical Organization Theory 10(1), Kluwer Academic Publisher, 69-94.

Sabherwal, R., \& Becerra-Fernandez, I. (2011). Business Intelligence: Practices, Technologies, and Management. USA: Wiley.

Schaffer, N. (2011). Maximizing Linkedin for Sales and Social Media Marketing: An Unofficial, Practical Guide to Selling \& Developing B2B Business on LinkedIn. WindMill Networking.

Scott, J. (2000). Social network analysis: A handbook (2nd ed.). London: SAGE Publications Ltd.

Sie, R. L. L., Bitter-Rijpkema, M., \& Sloep, P. B. (2011). What's in it for me? Recommendation of Peers in Networked Innovation. Journal of Universal Computer Science, 17(12), 1659-1672.

Takac, C., Hinz, O., \& Spann, M. (2011). The social embeddedness of decision making: opportunities and challenges. Electronic Markets, 21(3), 185-195. doi:10.1007/s12525-011-0066-y.

Vine, D. (2000). Internet Business Intelligence. USA: Thomas H. Hogan.

Wasserman, S., \& Faust, K. (1994). Social network analysis: Methods and applications. New York: Cambridge, University Press. 